\title{
The 14th Dalai Lama's Image on Western and Chinese Social Media
}

\author{
Mao Wei \\ Tsinghua University, Beijing, China
}

\begin{abstract}
With China's rising status and the increasing of media exposures on Tibet issues, the 14th Dalai Lama's image studies have become a heated research topic in communication studies. China is the most-frequently studied nation in Asian mass communication research. The past the 14th Dalai Lama's image studies mainly focus on Western mainstream newspapers, due to the fact that these newspapers are well established and frequently read by policy-makers and other influential individuals. In recent years, "Social media" has become a new buzzword. Social media platforms like Facebook, Twitter and Weibo etc. have made a considerable impact on contemporary life. What is the 14th Dalai Lama's image as it is represented via Western social media? Do Western social media publish the 14th Dalai Lama's different contents, from a different perspective, or in a different way from that of the standard Western mainstream news outlets? Are there any differences between the image of the 14th Dalai Lama on Western social media and on mainstream media? What are differences between the image of the 14th Dalai Lama on Western and Chinese social media when discussing the same event or topic? The research aims to answer these questions the 14th Dalai Lama; Western social media; Chinese social media.
\end{abstract}

Keywords: Dalai Lama, Tibet, Chinese social media, Western social media

\section{Introduction}

With China's rising status and the increasing of media exposures on Tibet issues, studies on the 14th Dalai Lama's image have become a heated research topic in journalism and communication. In recent years, China's journalism and communication research have made great progress, but it seems that most of the research on Tibet and the 14th Dalai Lama were mainly focus on the analysis on Western mainstream newspapers and websites. It is knowledgeable that the Western mainstream media are well established and widely read by influential persons and policy-makers from government, but "Social media" has become a new buzz phrase and some social media platforms like Twitter, Facebook and Weibo etc. have made a substantial impact on contemporary life. Kaplan and Haenlein (2010) defined the social media as Web 2.0 internet-based applications and user-generated content is the lifeblood of the social media organism (Obar \& Wildman, 2015).

Dependent on professional reporters and journalists, mainstream media are fully situated within the ideological norms of society, enjoy a widespread scale of influence, and are considerable connected with other corporate and governmental entities. Mainstream media are trapped within entrenched norms and values that predispose a certain perspective of the world (Kenix, 2011). However, social media may construct a media that

Mao Wei, Ph.D. Candidate, School of Journalism and Communication, Tsinghua University. 
is different from the mainstream and deconstruct the dominant discourse especially on hot topics in the world. (Hamilton, 2000).

What is the 14th Dalai Lama's image as it is represented via Western social media? Do Western social media publish the 14th Dalai Lama's different contents, from a different perspective, or in a different way from that of the standard Western mainstream news outlets? Are there any differences between the image of the 14th Dalai Lama on Western social media and on mainstream media? What are differences between the image of the 14th Dalai Lama on Western and Chinese social media when discussing the same event or topic? The research aims to answer these questions.

\section{Literature Review}

\section{News and Forming Images}

The 14th Dalai Lama's image is the product of a complex historical process involving the interplay of such factors as the political and social realities of China, PRC's diplomatic relations, and changes in the international political and economic spheres, as well as symbolic representations in the mass media and popular culture (PENG, 2004). Among these factors, news media play a vital role in constructing and shaping the image of the 14th Dalai Lama (Adoni \& Mane, 1984; Wolfsfeld, Avraham, \& Raiya, 1988). The reports would frame contexts of ideology, policy and culture while representative images will be produced for individuals use to picture the world in their heads and construct their conception of "us" and "them" (Kellner, 1995).

Walter Lippmann noted that the news media are a primary source of those pictures in our heads about the larger world of public affairs, a world that for most citizens is "out of reach, out of sight, out of mind" (Lippmann, 1922). What we know about the world, therefore, is largely based on what the media decide to tell us. More specifically, the result of this mediated view of the world is that the priorities of the media strongly influence the priorities of the public. Elements prominent on the media's agenda become prominent in the public mind (McCombs, 2004).

There are several ways to examine the influence of media on public attitudes, such as news construction and news framing theories. Shoemaker and Reese (1996) claim that "News is a socially created product, not a reflection of an objective reality" (p. 121). Behind the social construction of news, one of the most important factors in news coverage is framing. Norris (1995) defines news frames as cognitive schemata, and journalists commonly work with news frames to simplify, prioritize and structure the narrative flow of events. Framing is inevitable in the process of news production. It is the stage at which journalists define problems, diagnose causes and make moral judgments (Akhavan-Majid \& Ramaprasad, 2000).

In communication and journalism theory, framing is a schema of interpretation, a collection of anecdotes and stereotypes, that individuals rely on to understand and respond to events (Goffman, 1974). Also, framing is a procedure that selecting and emphasizing some issues, making connections among them so as to promote a particular interpretation, evaluation or solution (Entman, 2004). According to Druckman (2001), framing is generally considered in one of two ways: as frames in thought, consisting of the mental representations, interpretations, and simplifications of reality, and frames in communication, consisting of the communication of frames between different actors. It is an inevitable process of selective influence over the individual's perception of the meanings attributed to words or phrases. Through giving a serious of images or symbols, media can make a nation or a person real and tangible to audiences, while to some extent, these ware merely symbolic referents and imagined (Scannell \& Cardiff, 1995, Anderson, 1991). 


\section{Western Mainstream News and the 14th Dalai Lama's Image}

Due to China's rising international status, Tibet and the 14th Dalai Lama has long been and is still the focus of international communications studies. ZHANG \& LI (2006) studied New York Times' news reports on Tibet from 1999 to 2001 through quantitative and qualitative analysis. They concluded that there is strong bias when New York Times reported Tibet. Through analyzing how Washington Post and New York Times reported "3.14 Lhasa Riots" happened in 2008, LIU (2012) conclude that Western media magnified the negative effects of the activity and constructed the image that Tibetan were fighting for their own liberty and the "Holly Spirit" Tibet was gone under the control of CCP. HOU (2012) analyzed articles about 14th Dalai Lama in New York Times from 1979 to 2011. She found that there is a news framework when reporting 14th Dalai Lama and New York Times constructed an positive even perfect image of Chinese "Buddhism Leader", "Defender of Peace" and "Political Star" to him. Other scholars such as LIU (2006), GUO (2010), WANG et al. (2010) etc. also have done some studies on how Le Monde (France), Die Welt (German), and The Times (UK) imaging the Tibet and 14th Dalai Lama. These domestic research found that, although the economic and social development of Tibet has been rapidly increased, also the living standards of Tibetans have been greatly improved, Western mainstream newspapers still reported the Tibet and the 14th Dalai Lama in their "old tone".

\section{Social Media and the 14th Dalai Lama's Image}

Social media such as Blogs, BBS, Digg, Facebook, Twitter, Weibo and Wechat etc. are highly interactive platforms through individuals and communities share, co-create, discuss, and modify user-generated content. The report from Universal McCann (2011) showed that $96 \%$ of under 30-year old people (which is over half of the world population) in the world has joined the social networks and they visited Facebook, read blogs and share their ideas every day. According to Nuttney (2010) and Koetsier (2013), social media offers advertisers access to about 80 percent of global consumer expenditures, a \$29 trillion market and more than 15 million brands globally are registered with Facebook, one of the most popular social media site. The latest report from China Internet Network Information Center (CNNIC) showed that Chinese web users reached 688 million in December 2015, of which social media users in Weibo, WeChat, Blog etc. accounted for $77 \%$, about 500 million. Social networks have become influential hubs of inter-connected communities.

In the book We the Media: Grassroots Journalism by the People, for the People, social media is also referred to as "We Media" (Gillmor, 2006). Also, the growing popularity of alternative media, participatory media, collaborative media, open-source journalism, user-generated content and personal media etc. is based on the development of social media. In social media, individuals are no longer traditional audiences as passive receivers but producers of information while they have become active participants as producers or publishers in the process of information communication using Web publishing tools and powerful mobile devices (Shayne \& Chris, 2011). An important gist of social media is sharing and automatic production of information for general public while digital content and peer-to-peer interaction is created (Ivan, 2011).

Relying on professional reporters and editors, mainstream media enjoy an extensive scale of influence and closely connected with government, universities, large companies and other influential institutions and groups. Nowadays, several mainstream news media have experiment with social media tools to attract more users and readers while that platform has connected one-third of the world's population (Nelson-Field \& Taylor, 2012) and Jeremy (2009) pointed out that $70 \%$ of journalists in traditional media use social networks to report. 
According to Hamilton (2000), social media could build an alternative media which showed a social order different even opposed to the dominant order made by mainstream media. However, whether social media can jump from mainstream's structural constraints or ideological especially in international issues is a debated subject.

Previous studies on the 14th Dalai Lama's image have mainly focused on the traditional Western newspapers while almost no research paid close attention to them as showed through Internet. There is no comparison analysis on between Western media and Chinese media, particularly on social media which may be not controlled by the mainstream media.

\section{Research Questions}

Borrowing a term from Gramsci (1971), we may say the image of the 14th Dalai Lama represented by Western mainstream media is "hegemonic". Can Western social media give public a "counterhegemonic" image of it? Do social media report the 14th Dalai Lama mainly not shown in the mainstream media, from a different perspective that may not be accepted by the mainstream newspaper, and may not be found in mainstream content? With these as foundations, this research will explore how Western social media constructed the 14th Dalai Lama's image.

The components that link to "image" can be classified as economic, political, cultural images, etc. by their association to the news content. Therefore, this study will analyze the 14th Dalai Lama's image from the aspect of the news items' political, economic, cultural, social, technological and religious contents.

\section{Method}

\section{Research Approach and Research Objects}

The content analysis methodology has been used in this study. Several types of influential social media will be selected as the research objects such as blogs, microblogs (Twitter, Weibo), SNS (Facebook, Wechat Official Accounts), video sharing site (YouTube, Youku) and BBS (i.e., Topix) etc. Then, specific social media sites were selected from each of these types for the research. Considering the dominant role of English-language social media, except for Chinese, the specific social media sites are all English-language social media.

\section{Data Collection and Coding Unit}

The data collection will cover a one-year period, from 1 January through to 31 December, 2015. Each research site will be searched with the keywords "Dalai Lama" in headline and " 2015 " in date. After that, the searched posts will be sorted in terms of the number that audience viewed. For each sites, about 200-500 of the most-viewed news reports, many of which contained comments by that site's users, were downloaded. As the research is exploratory in nature, random sampling will not be applied. (Refer to Tables 1 and 2 for the number of samples collected from each site). The study collected 1,397 English items and 1,335 Chinese items to use as samples for the analysis in total.

Also, a coding book has been designed according to previous studies to analyze the coverage on 14th Dalai Lama. Each news item need to be coded in terms of its sources, theme, tone, issue, people and places concerned with etc.

Source of information will be categorized into DIY (Do It Yourself), repasted from other media, DIY-Repasted and unspecified. If it is repasted, further analysis will be conducted: Western mainstream, 
Western social media, Western Other, Chinese official media, Chinese commercial, Chinese social media and Other. To each source, its source country has also been traced.

The themes are persistent patterns of cognition, interpretation and presentation of selection, emphasis and exclusion. Generally, the themes contain politics, economy, international relations, social issues, culture, environment, education, military, science and technology, sports, ethical issues, religion and other.

Tone will refer to the degree that news items portray the 14th Dalai Lama in terms of positive or negative light. Tone of coverage was evaluated as most positive, more positive, neutral, more negative and most negative range.

Table 1

Research Objects (English)

\begin{tabular}{lll}
\hline Social media type & Research objects & Sampling amount \\
\hline Blog & Wordpress & 298 \\
Microblog & Twitter & 312 \\
SNS & Facebook & 326 \\
Video sharing site & YouTube & 116 \\
BBS & Topix & 345 \\
Total sampling amount & & 1,397 \\
\hline
\end{tabular}

Table 2

Research Objects (Chinese)

\begin{tabular}{lll}
\hline Social media type & Research objects & Sampling amount \\
\hline Blog & Sinablog & 288 \\
Microblog & Weibo & 97 \\
SNS & Wechat Official Accounts & 396 \\
Video sharing site & Youku & 89 \\
BBS & Tianya & 465 \\
Total sampling amount & & 1,335 \\
\hline
\end{tabular}

\section{Coding}

Eight research assistants were recruited from School of Journalism and Communication, Tsinghua University based on their research skills and language capabilities. They were trained in our coding scheme before coding. To reach an acceptable level of reliability, four research assistants codified and contrasted our findings on the same unit of analysis.

Then, a pilot study was conducted to ensure that the categories were clearly defined and well understood by the researchers. The analysis of all the news items that produced inter-coder reliability was above 0.8 using Cohen's Kappa (1960) formula which allowed us to determine the reliability of nominal data in terms of percentage of agreement.

\section{Main Findings}

\section{The 14th Dalai Lama's Image on Western Social Media}

Due to its rising status and frequent international events, Tibet and the 14th Dalai Lama have become a heated topic on western social media. In terms of the different views of images (political, cultural, social, religious and ethical), religious, political and ethical issues are the most reported topics on western social media. According to the sample of collected items, the most-discussed topic is religious issues, with 433 items 
(30.99\%); followed by political issues with 395 items (21.12\%) and ethical issues with 212 items (15.18\%); cultural topics, 123 items (8.74\%); social issues, 113 items (8.09\%)and other, 121 items. Refer to Table 3 for a more detailed breakdown of the findings.

Table 3

Themes Reported on Western Social Media

\begin{tabular}{lcc}
\hline Theme & Frequency & Percent \\
\hline Politics & 395 & $28.27 \%$ \\
Culture & 123 & $8.74 \%$ \\
Social issues & 113 & $8.09 \%$ \\
Religion & 433 & $30.99 \%$ \\
Ethic & 212 & $15.18 \%$ \\
Other & 121 & $8.73 \%$ \\
Total & 1,397 & $100 \%$ \\
\hline
\end{tabular}

The 14th Dalai Lama's image of a spiritual leader. The 14th Dalai Lama has been widely recognized as a spiritual leader or a religious leader that shared the same stage as "The Pop" among users of western social media. There were repeated stories about the 14th Dalai Lama's advocacy for the welfare of Tibetans, investigation on the interface between Buddhism and science and speech about the importance of compassion as the source of a happy life. "Tibet's exiled spiritual leader", "the exiled Tibetan Buddhist leader" and "the exiled Tibetan religious leader" were the most frequently used keywords to describe the 14th Dalai Lama on the western social media.

The 14th Dalai Lama's image of a pacifist. The 14th Dalai Lama received the Nobel Peace Prize in 1989, and he is known for his advocacy for Tibetans and teaching Tibetan Buddhism around the world in West, meanwhile, this has boosted his image as a pacifist. The western social media reflects this image; it reports positively on the 14th Dalai Lama's activity and policy. Keywords used by social media to describe the 14th Dalai Lama been as a pacifist included: "a winner of the Nobel Peace Prize" and "one of the world's most prominent advocates of nonviolence".

The 14th Dalai Lama's image of a political star. In 1959, the 14th Dalai Lama fled to India, where he currently lives as a political refugee. Since then, "Tibet issue" has been an increasing political topic on the media and "Agenda setting" as well as "Frame setting" were always hidden in western mainstream media reports (LIU, 2011), which has significant effect on western audiences' impression on the 14th Dalai Lama. Although there was not a descriptive report to show the 14th Dalai Lama as a political star, his policies such as "Strasbourg Statement" and activities such as being met by President of US, President of France and Premier of German etc. have been extensively reported on western social media, which potentially give the 14th Dalai Lama an image of a political star.

The 14th Dalai Lama's image on Chinese social media. Historically the Dalai Lamas or their regents held political and religious influence over all or most of the Tibetan plateau from Lhasa with varying degrees of autonomy. However, the 14th Dalai Lama fled to India in 1959 and he established the Central Tibetan Administration in Exile to carry out the Tibetan struggle for "independence" and "genuine autonomy" since then. It seems that reports on the 14th Dalai Lama in China belong to the sensitive information. When searching on one of the biggest SNS platform, Renren, in both Chinese and English character of Dalai Lama, an reminder page will come out to give these words that "According to the relevant laws, regulations and policies, search 
results did not show!". Researchers met the same situation when study in so-called China's twitter, Weibo, except that related results will be given when search in English.

In stark contrast, researchers found that the 14th Dalai Lama's image on Chinese social media was negative and "a Liar" and "a Traitor" were the most frequently used keywords to describe the 14th Dalai Lama, meanwhile, based on the sample of collected items, political, religious and ethical issues are the most reported topics while culture, social issues and others were almost none. Refer to Table 4 for a more detailed breakdown of the findings.

Table 4

Themes Reported on Chinese Social Media

\begin{tabular}{lcc}
\hline Theme & Frequency & Percent \\
\hline Politics & 842 & $63.07 \%$ \\
Culture & 21 & $1.57 \%$ \\
Social issues & 11 & $0.82 \%$ \\
Religion & 233 & $17.45 \%$ \\
Ethic & 221 & $16.55 \%$ \\
Other & 7 & $0.52 \%$ \\
Total & 1,335 & $100 \%$ \\
\hline
\end{tabular}

\section{Sources of the 14th Dalai Lama's Content on Social Media}

The 14th Dalai Lama's content on social media is mainly repasted from mainstream news media. Previous research showed that citizens will produce $50 \%$ of the news peer-to-peer (Shayne \& Chris, 2011). However, contents produced by social media are not that much, but mainly repasted from other media. Of the 1,397 items collected from Western social media and 1,335 items collected from Chinese social media, only 1,199 and 983 noted their sources respectively. The analysis on Western social media showed that, 795 (49.8\%) items were repasted from other media, while only 139 pieces $(19.98 \%)$ were created or produced by social media users. 111 pieces (18.94\%) were repasted, with comments added at the same, while the analysis on Chinese social media also showed the similar results. Table 5 details the findings.

Table 5

Source Type of the 14th Dalai Lama's Content on Western Social Media

\begin{tabular}{lcccr}
\hline \multirow{2}{*}{ Source type } & \multicolumn{2}{c}{ Western social media } & \multicolumn{2}{c}{ Chinese social media } \\
\cline { 2 - 5 } & Frequency & Percent & Frequency & Percent \\
\hline DIY & 189 & $15.76 \%$ & 21 & $2.14 \%$ \\
Repasted & 795 & $66.31 \%$ & 699 & $71.11 \%$ \\
DIY+Repasted & 113 & $9.42 \%$ & 211 & $21.46 \%$ \\
Unspecified & 102 & $8.51 \%$ & 52 & $5.29 \%$ \\
Total & 1,199 & $100 \%$ & 983 & $100 \%$ \\
\hline
\end{tabular}

Table 5 showed that news items conveyed by social media tend not to be actually generated by its users, but repasted from other media. In this case, social media does not function as an information producer, but instead serves as a recycling platform for previously generated content.

Traditional mainstream media are the main source of the 14th Dalai Lama's news conveyed by social media. When analyzing where the news found on the both Western and Chinese social media originated, we found that traditional mainstream media were the main sources of the 14th Dalai Lama-related news. Of the 
1,397 items in our database of Western social media, it was found that 795 items were directly repasted from other media, meanwhile, there were 699 items in the database of Chinese social media.

In the case of Western social media, the western mainstream media accounted for a staggering 653 recycled items $(82.14 \%)$, followed by western social media with 94 items (11.82\%), Chinese domestic media and Chinese social media accounted only $2.89 \%$ (23 items) and $1.51 \%$ (12 items) respectively. In comparison, Chinese mainstream media took a dominant role while the western source had a small effect on the news that Chinese social media users repost. Table 6 has more details on this piece of the analysis.

Table 6

Specific Sources of the 14th Dalai Lama's Contents on Social Media

\begin{tabular}{lcccc}
\hline \multirow{2}{*}{ Specific source type } & \multicolumn{2}{c}{ Western social media } & \multicolumn{2}{c}{ Chinese social media } \\
\cline { 2 - 5 } & Frequency & Percent & Frequency & Percent \\
\hline Western mainstream & 653 & $82.14 \%$ & 48 & $6.87 \%$ \\
Western social media & 94 & $11.82 \%$ & 11 & $1.57 \%$ \\
Chinese official media & 23 & $2.89 \%$ & 545 & $77.97 \%$ \\
Chinese social media & 12 & $1.51 \%$ & 63 & $9.01 \%$ \\
Other & 13 & $1.64 \%$ & 32 & $4.58 \%$ \\
Total & 795 & $100 \%$ & 699 & $100 \%$ \\
\hline
\end{tabular}

According to agenda-setting theory, first developed by McCombs and Shaw (1971), through highlighting certain issues, mass media could successfully set the agenda for public opinion. Previous research on the way political campaigns were covered in the media showed that the news media's main effect lay in agenda-setting such as telling people what not to think, but what to think about. The findings from these study indicate that the traditional mainstream media tend to influence the news that social media users repost to their followers and talk about to a great degree.

Table 7

Western Mainstream Media Outlets Repasted (Frequency >=11)

\begin{tabular}{llll}
\hline No. & Media outlets & Frequency repasted & Country \\
\hline 1 & New York Times & 136 & USA \\
2 & BBC & 122 & UK \\
3 & Reuters & 77 & UK \\
4 & The Wall Street Journal & 45 & USA \\
5 & Time & 31 & USA \\
6 & Bloomberg & 29 & USA \\
7 & Washington Post & 21 & USA \\
8 & CNN & 19 & USA \\
9 & Los Angeles Times & 19 & USA \\
10 & Telegraph & 17 & UK \\
11 & Yahoo & 14 & USA \\
12 & ABC & 14 & USA \\
13 & CBS & 13 & USA \\
14 & AFP & 13 & France \\
15 & Guardian & 12 & UK \\
16 & The Times of India & 11 & India \\
17 & Economist & 11 & UK \\
18 & FOX & 11 & USA \\
\hline
\end{tabular}


The mainstream media outlets that indicated the largest frequency of recycling included New York Times, Wall Street Journal, Time, Bloomberg, Washington Post, CNN, Los Angeles Times, Yahoo, ABC, CBS, Fox from the USA, BBC, Reuters, Telegraph, The Guardian, The Economist from UK, AFP from France and The Times of India from India when analyzing on the Western social media. The frequency of overseas mainstream media re-use is detailed in Table 7.

The analysis also showed that western social media sites also recycled items amongst themselves. Among social media, Twitter, YouTube and Facebook were repasted most. For the frequency of international social media repasted, refer to Table 8 .

Table 8

Western Main Social Media Repasted (Frequency > = 5)

\begin{tabular}{llcc}
\hline No. & Media outlets & Frequency repasted & Country \\
\hline 1 & Twitter & 124 & USA \\
2 & Youtube & 98 & USA \\
3 & Facebook & 96 & USA \\
4 & Digg & 29 & USA \\
5 & Wordpress & 15 & USA \\
6 & Business Insider & 11 & USA \\
7 & Boingboing.net & 7 & USA \\
8 & MSN & 5 & USA \\
9 & Imgur.com & 5 & USA \\
\hline
\end{tabular}

US and UK media dominate the information on Western social media. The news media in developed countries appear to serve as the primary source of information that flows through the social media. Of the 1199 items noted the sources, the USA accounted for 599 pieces (49.96\%) followed by the UK with 301 pieces (25.10\%). Items repasted from US and UK media totaled $75 \%$. According to these numbers, an argument could be made that the US and UK mainstream media outlets serve as the primary sources of information on the 14th Dalai Lama that appears in western social media.

Among all the reportage recorded in the collected samples, 49 items (4.09\%) are from Chinese media outlets, $22(1.83 \%)$ from India and $29(2.42 \%)$ from Canada. Except for the above-named countries, the number of items recycled from other countries' news outlets totaled less than 15 pieces. Please refer to Table 9 for more details.

Table 9

Source Country Repasted (Frequency >= 5)

\begin{tabular}{lcc}
\hline Country & Frequency & Percent \\
\hline USA & 599 & $49.96 \%$ \\
UK & 301 & $25.10 \%$ \\
China & 49 & $4.09 \%$ \\
India & 22 & $1.83 \%$ \\
Canada & 29 & $2.42 \%$ \\
Australia & 15 & $1.25 \%$ \\
France & 11 & $0.92 \%$ \\
Russia & 5 & $0.42 \%$ \\
Japan & 5 & $0.42 \%$ \\
\hline
\end{tabular}


It should be noted that the amount of news items re-pasted from Chinese media outlets was quite small, only $8 \%$ that of USA. Among the official Chinese media outlets, China Daily items were reposted 16 items, followed by the Xinhua News Agency (China's official news agency) with 14 items. For China Central Television Station (CCTV), the People's Daily (China's official newspaper) and China.org (China's official online website) the numbers were only 6,4 , and 3 re-postings respectively. See Table 10 for more information.

Table 10

Chinese Official Media Outlet Repasted (Frequency >=3)

\begin{tabular}{lll}
\hline No. & Media & Frequency \\
\hline 1 & China Daily & 16 \\
2 & Xinhua News Agency & 14 \\
3 & CCTV & 6 \\
4 & the People's Daily & 4 \\
5 & China.org & 3 \\
\hline
\end{tabular}

\section{Discussion and Conclusion}

Based on the assumption that social media is an alternative media that may offer a "counter-hegemonic" image of the 14th Dalai Lama, this study explored his image as constructed by some representative and influential Western and Chinese media with a content analysis methodology.

This study found that Western and Chinese social media present a totally different picture of the 14th Dalai Lama. Western social media focuses more on religious, political and ethical issues and views the 14th Dalai Lama extremely positive as a spiritual leader, a pacifist and a political star, while Chinese social media negatively frame the 14th Dalai Lama's image as "a Liar" and "a Traitor".

Moreover, it should be noted that Western traditional mainstream media are the main sources of the 14th Dalai Lama's news conveyed by Western social media and the users repasted the 14th Dalai Lama news items from Chinese media outlets was quite small. Furthermore, Western social media users do not actually generate much original news content on their own, therefore, the US and UK mainstream media appears to play an influential role in the construction of the 14th Dalai Lama's image. The mainstream media not only set the agenda for international social media in reporting the 14th Dalai Lama, but also influence the frame. Therefore, it may be concluded that social media may not offer a more neutral, objective and diverse view of the 14th Dalai Lama.

Limitations and future directions: Though this study intends to compare the difference of the image presented on social media and traditional mainstream media, it only researches the image presented on social media, while the traditional mainstream media's images of the 14th Dalai Lama are mainly drawn from the literature. While these sources are effective in illustrating the study's findings, reliance on them might also lessen the impact of any conclusions that could be drawn. And the Chinese database had some internal shortness, for instance, when searching on one of the biggest SNS platform, Renren, in both Chinese and English character of Dalai Lama, an reminder page will come out to give these words that "According to the relevant laws, regulations and policies, search results did not show!". To make the comparison more objective and scientific, coverage of the 14th Dalai Lama by both traditional mainstream media and social media during the same time period should be studied and a statistical analysis on both Western and Chinese social media users should be conducted. 
What's more, this research is tentative in nature, and the non-random sample does not allow us to generalize the findings. Future studies should be directed to a more systematic and scientific sampling.

\section{References}

Adoni, H., \& Mane, A. (1984). Media and the social construction of reality: Toward an integration of theory and research. Communication Research, 11(3), 323-40.

Akhavan-Majid, R., \& Ramaprasad, J. (2000). Framing Beijing: Dominant ideological influences on the American press coverage of the Fourth UN conference on Women and the NGO forum. Gazette. The International Journal for Communication Studies, $62(1), 45-59$.

Cohen, J. (1960). A coefficient of agreement for nominal scales. Educational and Psychological Measurement, 20(3), 7-46.

Druckman, J. N. (2001). The implications of framing effects for citizen competence. Political Behavior, 23(3), 225-256.

Entman, R. (1993). Framing: Toward a clarification of a fractured paradigm. Journal of Communication, 43(4), 51-8.

Entman, R. (2004). Projections of power: Framing news, public opinion and U.S. foreign policy. Chicago: University of Chicago Press. Gillmor, D. (2006). We the media: Grassroots journalism by the people for the people. California: O'Reilly Media.

Goffman, E. (1974). Frame analysis: An easy on the organization of experience. Cambridge, MA: Harvard University Press.

Gramsci, A. (1971). Selections from the prison notebooks of Antonio Gramsci. New York: International Publishers.

GUO, Y. H. (2011). Preliminary studies on Tibetan news reported by Times. Tibet Studies, 6, 91-100.

Hamilton, C. (2000). Changing subjects: Gendered identities in ETA and radical Basque nationalism. In B. Jordan, \& R. Morgan-Tamosunas (Eds.), Contemporary Spanish Cultural Studies (pp. 223-32). London: Arnold.

HOU, X. S. (2012). The representation of the 14th Dalai Lama in the New York Times. China Youth University for Political Science.

Ivan, W. (2011). Social media-An operating system For humans? Retrieved from http://www.ivanwalsh.com/social-mediastrategy/social-media-operating-system/

Jeremy, P. (2009). 70 percent of journalists use social networks to assist in reporting. Retrieved from http://blog.journalistics.com/2009/70-percent-of-journalists-use-social-networks-to-assist-in-reporting/

Kaplan, A. M., \& Haenlein, M. (2010). Users of the world, unite! The challenges and opportunities of social media. Business Horizons, 53(1). 61.

Kellner, D. (1995). Media culture: Cultural studies, identity, and politics between the modern and the postmodern. London and New York: Routledge.

Kenix, L. J. (2011). Alternative and mainstream media: The converging spectrum. London: Bloomsbury Academic.

Koetsier, J. (2013). Facebook: 15 million businesses, companies, and organizations now have a Facebook page. San Francisco, CA: VentureBeat.

Lippmann, W. (1922). Public opinion (p. 29). New York: Macmillan.

LIU, S. (2011). Dalai Lama image presented by New York Times: An analysis on Dalai-Related reports from 1980 to 2010. Shanghai Jiao Tong University.

LIU, X. Y. (2012). Analysis on how US mainstream newspaper report Tibet. Hebei University.

LIU, Y. (2006). Analysis on how Le Mond report Tibet. China Tibetology, 4, 67-74.

McCombs, M. (2004). Setting the agenda. Cambridge, England: Polity Press.

McCombs, M., \& Shaw, D. (1971). The agenda-setting function of mass media. Public Opinion Quarterly, 36, $176-85$.

Nelson-Field, K., \& Taylor, J. (2012). Facebook fans: A fan for life? Retrieved from http://www.warc.com/Content/LinkResolver.aspx?AID=96814\&M=admap_may12

Norris, P. (1995). The restless search light: Network news framing of the post-cold war. Political Communication, 2, 357-370.

Nuttney, A. (2010). The social networking market opportunity. Birmingham, AL: Insights.

Obar, J. A., \& Wildman, S. (2015). Social media definition and the governance challenge: An introduction to the special issue. Telecommunications Policy, 39(9), 745-750.

PENG, Z. (2004). Representation of China: An across time analysis of coverage in the New York Times and Los Angeles Times. Asian Journal of Communication, 14(1), 53-67.

Scannell, P., \& Cardiff, D. (1991). A social history of British broadcasting, 1, 1922-1939, serving the nation. Oxford: Blackwell. Shayne, B., \& Chris, W. (2011). We media-How audience are shaping the future of news and information. Retrieved from http://www.hypergen.net/wemedia/download/we-media 
Shoemaker, P., \& Reese, S. (1996). Mediating the message: Theories of influence on mass media content. NewYork: Longman. Universal McCann. (2010). Power to the people. Retrieved from http://www.umww.com/

WANG, Y. H., ZHANG, X. W., HE, S. M., DING, J., \& JIANG, X. C. (2010). Analysis on how German mainstream newspaper report Tibet issues. Journalism and Communication Studies, 2, 31-40.

Wolfsfeld, G., Avraham, I., \& Raiya, A. (1988). When property fails, every year: Israeli press coverage of the Arab minority land protests. Proceedings from 48th Annual Conference of the International Communication Association.

XIANG, D. B. (2013). China's image on international English language social media. Journal of International Communication, 19(2), 252-271.

ZHANG, Z. R., \& LI, J. (2006). Analysis on how New York Times report Tibet. External Communication, 12, 43-5. 